\title{
Metabolic factors accelerate colorectal adenoma recurrence
}

\author{
Leo Taniguchi ${ }^{1 \dagger}$, Takuma Higurashi ${ }^{2 \dagger}$, Takashi Uchiyama ${ }^{1 \dagger}$, Yoshinobu Kondo ${ }^{3 \dagger}$, Eri Uchida ${ }^{6 \dagger}$, Shiori Uchiyama ${ }^{4 \dagger}$, \\ Fumitake Jono ${ }^{5 \dagger}$, Jun Hamanaka ${ }^{7 \dagger}$, Hitoshi Kuriyama ${ }^{1 \dagger}$, Yasuo Hata ${ }^{1 \dagger}$, Hiroki Endo ${ }^{2+}$, Hirokazu Takahashi ${ }^{2 \dagger}$, \\ Hajime Nagase $^{4 \dagger}$, Nobuyuki Matsuhashi ${ }^{7 \dagger}$ and Atsushi Nakajima ${ }^{{ }^{*} \dagger}$
}

\begin{abstract}
Background: Metabolic factors have been reported to increase the prevalence of colorectal adenomas, however, whether metabolic factors might also accelerate the recurrence after removal of adenomas has not yet been discussed. In this retrospective multicenter study, we clarified the risk factors for adenoma recurrence focusing on metabolic factors.

Methods: We analyzed the medical records of 43,195 patients who had undergone colonoscopy between January 2005 and December 2011 at 5 hospitals in Japan. Of these, the data of 1111 patients who had undergone removal of adenomas at the first screening colonoscopy, and then been followed up by colonoscopy 1 year and 2 years later were analyzed.

Results: The following 8 factors were demonstrated with a multivariate analysis as being associated with colorectal adenomas recurrence: for adenoma-related factors, 5 factors (villous features, grade of dysplasia, location and size of the largest removed adenoma, and number of the removed adenomas) were identified; for metabolic factors and other factors, 3 factors (age, body mass index (BMI), and fasting blood glucose (FBG)) were identified. A risk score (0-10 points) was developed based on these 8 factors. The risk of adenoma recurrence increased as the risk score increased. When the risk score was $\geq 3$ (3-10) points, the odds ratio relative to $<3(0-2)$ points was 7.07 ( $95 \%$ Cls 5.30-9.43).

Conclusions: In addition to adenoma-related factors (villous features, grade of dysplasia, location, size and number), 3 factors (age, BMI and FBG) were demonstrated to influence the recurrence rate of colorectal adenoma. When the risk score was $\geq 3$, the risk of recurrence was significantly elevated.
\end{abstract}

Keywords: Metabolic factor, Colorectal adenoma recurrence

\section{Background}

Despite the recent advances in therapeutic modalities for colorectal cancer (CRC), it remains a major cause of mortality worldwide [1]. In most cases, CRC develops through the adenoma-carcinoma sequence, which serves as the rationale for screening and prevention of CRC by colonoscopic examinations. Colonoscopy with removal of adenomas is a powerful tool to reduce the mortality of CRC [1-3]. Surveillance colonoscopy is also recommended

\footnotetext{
* Correspondence: nakajima-tky@umin.ac.jp

${ }^{\dagger}$ Equal contributors

${ }^{2}$ Division of Gastroenterology, Yokohama City University School of Medicine, 3-9 Fukuura, Kanazawa-ku, 236-0004 Yokohama, Kanagawa, Japan
} Full list of author information is available at the end of the article after the initial endoscopic removal of adenoma, because of the possibility of development of new tumors [2,3].

In Japan, no guidelines have been established yet for surveillance colonoscopies. However, in the United States, the American Gastroenterological Association (AGA) guidelines are adopted as the basic protocols for colonoscopic surveillance after initial screening/removal of adenomas. These guidelines recommend stratification of patients at the time of the initial colonoscopy into groups at a low and high risk of subsequent development of more advanced tumors [2]. Patients who have advanced adenomas or multiple (3 or more) adenomas are classified into the high-risk group. Advanced adenomas are defined as adenomas that show high-grade dysplasia or $>20 \%$ villous component or measure $\geq 1 \mathrm{~cm}$ in size. Follow-up

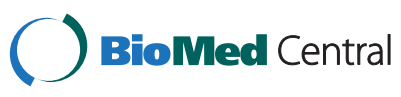


colonoscopy every 3 years is recommended for the highrisk group. Patients with other adenomas, namely, 1 or 2 small $(<1 \mathrm{~cm})$ tubular adenomas that do not show highgrade dysplasia, are classified into the low-risk group, and follow-up colonoscopy every 5-10 years is recommended for this group. In patients with hyperplastic polyps and those with only average risk, follow-up colonoscopy every 10 years is considered adequate.

Recently, in some studies, metabolic factors were shown to be associated with an increased prevalence of colorectal tumors. Limburg et al. and Elwing et al. demonstrated the association between diabetes mellitus and colorectal tumors $[4,5]$. Otani et al. and Liu et al. showed a relationship between dyslipidemia and colorectal tumors $[6,7]$. Kim et al. and Orranapalai et al. proved that metabolic syndrome was associated with colorectal tumors $[8,9]$. The incidence rates of metabolic factors have dramatically increased in developed countries as a result of the high prevalence of obesity [10]. Therefore, metabolic factors rank as important risk factors for the increase of prevalence of colorectal tumors. Metabolic factors have also been suggested as risk factors for recurrence after endoscopic removal of colorectal adenomas. To the best of our knowledge, however, no study as yet has discussed whether the presence of metabolic factors might accelerate the development of recurrence after endoscopic removal of colorectal adenomas.

The aim of this study was to identify the risk factors for colorectal adenoma recurrence, focusing on metabolic factors, in addition to those adenoma-related factors that the AGA guidelines have established. We therefore constructed a scoring system with the identified risk factors for recurrence that could predict the recurrence rate according to the risk score.

\section{Methods}

\section{Study participants}

This multicenter retrospective study was conducted with the participation of 5 community hospitals in Japan, including Chigasaki Municipal Hospital, Yokohama Rousai Hospital, Tokyo Metropolitan Hiroo Hospital, Machida Municipal Hospital, and NTT Medical Center Tokyo. We analyzed the medical records of 43,195 patients who had undergone colonoscopy between January 2005 and December 2011 at any one of the 5 hospitals. Among these, only those who had undergone complete colonoscopy for the purpose of screening were enrolled in this study ( $\mathrm{n}=32,566$ ); the remaining 10,629 patients were excluded either because they had undergone colonoscopy for diagnostic purposes, or did not undergo complete colonoscopy. Next, 24,123 subjects who had not undergone removal of adenomas $\geq 5 \mathrm{~mm}$ in size at the time of the screening colonoscopy were excluded, and the remaining 8443 subjects who had undergone removal of adenomas $\geq 5 \mathrm{~mm}$ in size were included in this study (smaller adenomas have been shown to be of minimal clinical significance [11]). Furthermore, from among the 8443 subjects, we excluded 6703 subjects who did not undergo surveillance colonoscopy at 1 year and 2 years after the initial colonoscopy (that is, all the eligible patients enrolled in this study had undergone colonoscopy 3 times; colonoscopy is very cheap in Japan, and annual surveillance colonoscopies are common). To be eligible for this study, the participants had to have undergone complete colonoscopy at all the three examinations. A complete colonoscopy was considered to include: colonoscopy up to the level of the cecum, good bowel preparation, and removal of all the detected adenomas. Thereafter, further participants were excluded for the following reasons (total $\mathrm{n}=629$ ): no history or no laboratory data available $(\mathrm{n}=327)$; age less than 50 years old or greater than 85 years old $(n=120)$; history of colorectal resection or appendectomy $(\mathrm{n}=88)$; history of removal of carcinoma $(n=28)$; history of inflammatory bowel disease (IBD), familial adenomatous polyposis (FAP) or hereditary non-polyposis colorectal cancer (HNPCC) $(\mathrm{n}=18)$; history of regular use or use for over 7 days a month of aspirin or non-aspirin steroidal anti-inflammatory drugs (NSAIDs) $(\mathrm{n}=31)$; and patients with a life expectancy of less than 2 years because of severe diseases such as cancer, severe liver dysfunction, severe renal dysfunction, severe infection, etc. $(n=17)$; Finally, 1111 participants were included for the analysis in our study (Figure 1). To minimize the selection bias, all of the patients who had undergone colonoscopy at the 5 hospitals over the 7 -year period were assessed, and all of the patients who fulfilled the inclusion criteria but not the exclusion criteria were enrolled in this study.

The study protocol was approved by the individual ethics committees of each of the 5 participating hospitals, that are Chigasaki Municipal Hospital, Yokohama Rousai Hospital, Tokyo Metropolitan Hiroo Hospital, Machida Municipal Hospital, and NTT Medical Center Tokyo.

\section{Data collection}

A total of 20 data points at the initial colonoscopy and colorectal adenoma recurrence over the 2-year observation period were obtained from the medical records. The 20 items evaluated were: age at initial colonoscopy, gender, body mass index (BMI), current alcohol consumption, current cigarette smoking, the present history of hypertension, diabetes mellitus and dyslipidemia, fasting blood glucose (FBG), hemoglobin A1c (HbA1c), serum total cholesterol (TC), high-density lipoprotein cholesterol (HDL-C), low-density lipoprotein cholesterol (LDL-C) and triglycerides (TG), morphology/villous features/ grade of dysplasia/location/size of the largest removed adenoma, and number of removed adenomas. 


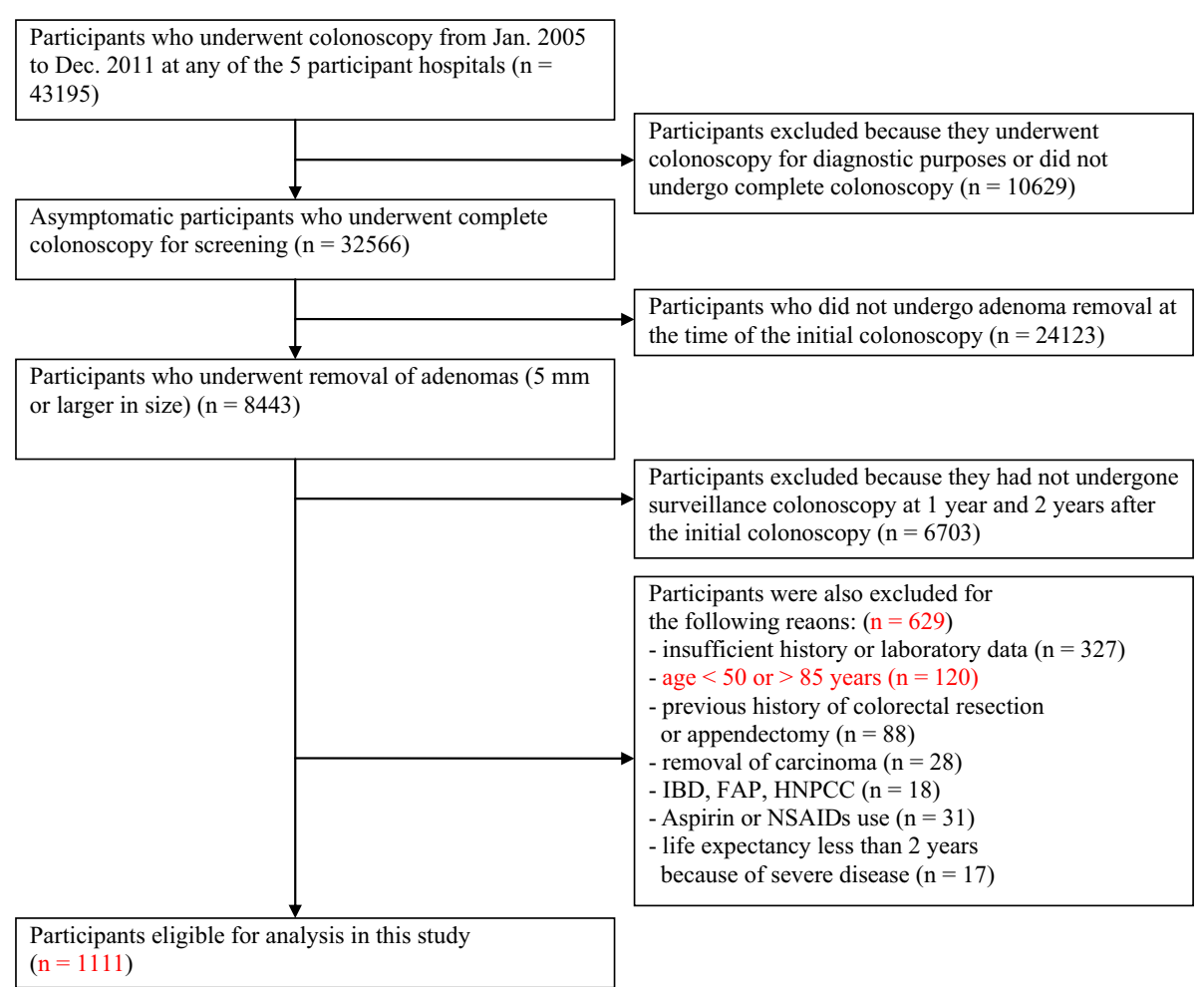

Figure 1 Inclusion and exclusion criteria of the study participants.

Siegel et al. showed that the prevalence of colorectal tumors increased in adults aged 65 and older [1]. So, age was categorized into $\geq 65$ and $<65$. BMI was calculated as the weight (in $\mathrm{kg}$ ) divided by height squared (in $\mathrm{m}^{2}$ ). Obesity was defined as BMI $\geq 25$ [12]. BMI was classified into $\geq 25$ and $<25$. Current alcohol intake history was defined as positive when the consumption was estimated to be in excess of $30 \mathrm{~g} /$ day. Present history of hypertension was defined as blood pressure $\geq 130 / 85 \mathrm{mmHg}$ and/or current use of antihypertensive medication [13]. Present history of diabetes mellitus was diagnosed if the patients had a random glucose level of $\geq 200 \mathrm{mg} / \mathrm{dl}$, FBG of $\geq 126 \mathrm{mg} / \mathrm{dl}$, HbA1c of $\geq 6.5 \%$ or were taking antidiabetic medication [14]. Present history of dyslipidemia was defined as TG $\geq 150 \mathrm{mg} / \mathrm{dl}$ and/or HDL-C $<40 \mathrm{mg} / \mathrm{dl}$ or were taking antidyslipidemic medication [13]. The FBG, HbA1c, TC, HDL-C, LDL-C, and TG were determined by laboratory testing at the time of the initial colonoscopy. FBG, HbA1c, HDL-C, and TG were classified into two groups with the above cutoff values. TC $\geq 220$ and $\mathrm{LDL} \geq 140$ were adopted as cutoff values according to the Japanese definition [15]. For the largest among the removed adenomas at the time of the initial colonoscopy, we determined the presence/absence of $>20 \%$ villous components, grade of dysplasia (high/low), location, and size. The location of the largest adenoma was classified as right-sided if it was in the cecum, ascending colon or transverse colon, and as left-sided if it was in the splenic flexure, descending colon, sigmoid colon or rectum. Colorectal adenoma recurrence was diagnosed if an adenoma (s) $\geq 5 \mathrm{~mm}$ in size was found in the surveillance colonoscopy, and both newly developed colorectal adenomas and colorectal adenomas recurring at the same location as that of the previously removed adenoma were included.

\section{Statistical analysis}

Statistical analysis was conducted using the JMP 10.0 software. Chi-square analysis was used to compare differences in variables. Univariate analysis was performed by logistic regression analysis. Multivariate analysis was performed by multiple logistic regression analysis. The correlation between the risk score and colorectal adenoma recurrence were assessed by analysis of the receiver operating characteristic (ROC) curves. Differences were considered statistically significant at $\mathrm{p}<0.05$.

\section{Results}

\section{Baseline characteristics and recurrence of colorectal adenomas}

The baseline clinical characteristics of the study participants with and without colorectal adenoma recurrence developing within 2 years of the initial colonoscopy are provided in Table 1 and clinical characteristics of the removed adenomas are shown in Table 2. 
Table 1 Clinical characteristics of the study participants ( $\mathrm{n}=\mathbf{1 1 1 1})$

\begin{tabular}{|c|c|c|c|}
\hline \multirow[t]{2}{*}{ Parameters } & \multicolumn{2}{|c|}{ Recurrence } & \multirow[t]{2}{*}{$P$ value } \\
\hline & Present (\%) & Absent (\%) & \\
\hline Total & $471(42.4)$ & $640(57.6)$ & \\
\hline Age (years) & & & 0.808 \\
\hline$\geq 65$ & $275(58.4)$ & $369(57.7)$ & \\
\hline$<65$ & $196(41.6)$ & $271(42.3)$ & \\
\hline Gender & & & 0.106 \\
\hline Male & $370(78.6)$ & $476(74.4)$ & \\
\hline Female & $101(21.4)$ & $164(25.6)$ & \\
\hline BMI $\left(\mathrm{kg} / \mathrm{m}^{2}\right)$ & & & $<0.001$ \\
\hline$\geq 25$ & $142(30.1)$ & $115(18.0)$ & \\
\hline$<25$ & $329(69.9)$ & $525(82.0)$ & \\
\hline Current alcohol consumption & & & 0.407 \\
\hline Yes & $265(56.3)$ & $376(58.8)$ & \\
\hline No & $206(43.7)$ & $264(41.3)$ & \\
\hline Current cigarette smoking & & & 0.011 \\
\hline Yes & $174(36.9)$ & $190(29.7)$ & \\
\hline No & $297(63.1)$ & $450(70.3)$ & \\
\hline Hypertension & & & 0.019 \\
\hline Yes & $280(59.4)$ & $335(52.3)$ & \\
\hline No & $191(40.6)$ & $305(47.7)$ & \\
\hline Diabetes Mellitus & & & $<0.001$ \\
\hline Yes & $149(31.6)$ & $129(20.2)$ & \\
\hline No & $322(68.4)$ & $511(79.8)$ & \\
\hline Dyslipidemia & & & 0.001 \\
\hline Yes & $172(36.5)$ & $176(27.5)$ & \\
\hline No & $299(63.5)$ & $464(72.5)$ & \\
\hline FBG (mg/dL) & & & $<0.001$ \\
\hline$\geq 126$ & $135(28.7)$ & $82(12.8)$ & \\
\hline$<126$ & $336(71.3)$ & $558(87.2)$ & \\
\hline HbA1c (\%) & & & $<0.001$ \\
\hline$\geq 6.5$ & $109(23.1)$ & $71(11.1)$ & \\
\hline$<6.5$ & $362(76.9)$ & 569 (88.9) & \\
\hline $\mathrm{TC}(\mathrm{mg} / \mathrm{dL})$ & & & 0.080 \\
\hline$\geq 220$ & $99(21.0)$ & $108(16.9)$ & \\
\hline$<220$ & $372(79.0)$ & $532(83.1)$ & \\
\hline $\mathrm{HDL}-\mathrm{C}(\mathrm{mg} / \mathrm{dL})$ & & & 0.176 \\
\hline$<40$ & $56(11.9)$ & $60(9.4)$ & \\
\hline$\geq 40$ & $415(88.1)$ & $580(90.6)$ & \\
\hline LDL-C (mg/dL) & & & 0.010 \\
\hline$\geq 140$ & $73(15.5)$ & $66(10.3)$ & \\
\hline$<140$ & 398 (84.5) & 574 (89.7) & \\
\hline TG (mg/dL) & & & $<0.001$ \\
\hline$\geq 150$ & $153(32.5)$ & 127 (19.8) & \\
\hline$<150$ & 318 (67.5) & $513(80.2)$ & \\
\hline
\end{tabular}

During the 2-year follow-up after the initial colonoscopy, 471 of the 1111 patients (42.4\%) were identified as having recurrence of colorectal adenomas whereas the remaining 640 patients $(57.6 \%)$ were free of recurrence (Table 1). Of the 471 , the recurrence was identified at the 1-year surveillance colonoscopy in 313 patients (28.2\%), and at the 2-year surveillance colonoscopy in the remaining 158 patients $(14.2 \%)$.

The characteristics of recurrent adenomas are demonstrated in Table 3. Among recurrent adenomas, advanced adenomas occupied $10.8 \%$ (51/471). Location of the largest recurrent adenomas tended to exist in the right-sided colon.

\section{Univariate analysis to identify the risk factors for adenoma recurrence}

Each of 20 risk factors evaluated was found to be statistically significant, except for the age, gender, current alcohol consumption, TC and HDL-C. Although older males were more likely to undergo adenoma removal at the time of the initial colonoscopy, age and gender were not identified as statistically significant factors influencing the risk of colorectal adenoma recurrence. While current alcohol consumption was not found to be statistically significant, current cigarette smoking was statistically significant. Metabolic factors such as the BMI, hypertension, diabetes mellitus and dyslipidemia were found to be statistically significant factors, as were the FBG, HbA1c, LDL-C and TG. Among the metabolic factors, TC and HDL-C were not statistically significant. In regard to the adenomarelated factors, non-polypoid lesion, presence of $>20 \%$ villous components, presence of high-grade dysplasia, a larger maximum diameter and a larger number of removed adenomas were found to be statistically significant risk factors for colorectal adenoma recurrence. Right-sided adenomas were associated with a higher risk of recurrence than left-sided adenomas. The odds ratio and $p$ value of each factor with univariate analysis are shown in Table 4.

\section{Multivariate analysis to identify independent risk factors for adenoma recurrence}

Multiple logistic regression analysis was performed with 15 of 20 risk factors. There was collinearity among a present history of diabetes mellitus, FBG and HbA1c. Among these 3 factors, FBG was used in the multivariate analysis because the odds ratios of FBG were maximum among these in the univariate analysis. There was also collinearity among a present history of dyslipidemia, TC, HDL-C, LDL-C and TG. The odds ratios of LDL-C and TG were greater than that of others, and the correlation coefficient between LDL-C and TG was low (correlation coefficient $=0.0992)$. So, among these factors, LDL-C and TG were used in the multivariate analysis.

The results from the multivariate analysis identified 7 factors, namely, age, BMI, FBG, dysplasia grade/location/ 
Table 2 Clinical characteristics of the removed adenomas $(n=1111)$

\begin{tabular}{|c|c|c|c|}
\hline \multirow[t]{2}{*}{ Parameters } & \multicolumn{2}{|c|}{ Recurrence } & \multirow[t]{2}{*}{$P$ value } \\
\hline & Present (\%) & Absent (\%) & \\
\hline Total & $471(42.4)$ & $640(57.6)$ & \\
\hline Morphology of the largest adenoma & & & $<0.001$ \\
\hline Non-polypoid lesion & 79 (16.8) & $48(7.5)$ & \\
\hline Polypoid lesion & $392(83.2)$ & $592(92.5)$ & \\
\hline$>20 \%$ Villous features of the largest adenoma & & & $<0.001$ \\
\hline Yes & $178(37.8)$ & $145(22.7)$ & \\
\hline No & $293(62.2)$ & $495(77.3)$ & \\
\hline Degree of differentiation of the largest adenoma & & & $<0.001$ \\
\hline high grade & $199(42.3)$ & $114(17.8)$ & \\
\hline low grade & $272(57.7)$ & $526(82.2)$ & \\
\hline Location of the largest adenoma & & & 0.028 \\
\hline Right-sided colon & $250(53.1)$ & $297(46.4)$ & \\
\hline Left-sided colon & $221(46.9)$ & $343(53.6)$ & \\
\hline Diameter of the largest adenoma (mm) & & & $<0.001$ \\
\hline$\geq 10$ & $300(63.7)$ & $161(25.2)$ & \\
\hline$<10$ & $171(36.3)$ & $479(74.8)$ & \\
\hline \multicolumn{4}{|l|}{ Number of the removed adenomas } \\
\hline$\geq 3$ & $320(67.9)$ & $121(18.9)$ & $<0.001$ \\
\hline$<3$ & $151(32.1)$ & $519(81.1)$ & \\
\hline
\end{tabular}

size of the largest adenoma, and number of the removed adenomas as being statistically significant factors influencing the risk of colorectal adenoma recurrence. Villous features were almost statistically significant $(p=0.063)$. The odds ratio and $\mathrm{p}$ value of each factor from the multivariate analysis are shown in Table 5.

\section{Scoring system for calculating the recurrence rate of colorectal adenomas}

Analysis was performed using 8 factors (Table 5): For adenoma-related factors, 5 factors, namely, villous features/

\section{Table 3 Characteristics of recurrent adenomas $(n=471)$}

\begin{tabular}{lr}
\hline Number of recurrent adenomas, median [interquartile range] & $1[1-2]$ \\
$\begin{array}{l}\text { Diameter of the largest adenoma, median } \\
\text { [interquartile range] }\end{array}$ & $5[5-8]$ \\
Appearance (\%) & $20(4.2)$ \\
$\quad$ Non-polypoid lesion & $451(95.8)$ \\
Polypoid lesion & 51 (10.8) \\
Pathology (\%) & 420 (89.2) \\
Advanced adenoma & \\
Non-advanced adenoma & 290 (61.6) \\
Location of the largest adenoma (\%) & 191 (38.4) \\
Right-sided colon & \\
\hline
\end{tabular}

grade of dysplasia/location/size of the largest adenoma, and number of the removed adenomas were included. For metabolic factors and other factors, 3 factors, namely, age, BMI, FBG were included. Seven of 8 factors were adopted because they were statistically significant in the multivariate analysis. Villous features were included because it was an established risk factor in the AGA guidelines, and was also nearly statistically significant in our study in the multivariate analysis including metabolic risk factors.

One point was scored for if each positive factor. But, because the odds ratio of the number of removed adenomas in the multivariate analysis was almost 3 times bigger than that of other factors, the number of removed adenomas counted as 3 points if it was positive. The risk score was calculated by summing up each individual score, and ranged from 0 to 10 points.

The correlation between the risk score $(0-10$ points) and colorectal adenoma recurrence during the 2-year follow-up after the initial colonoscopy was analyzed with a logistic regression analysis, which revealed a statistically significant correlation ( $\mathrm{p}<0.001$ ).

ROC curve analysis revealed an AUROC for colorectal adenoma recurrence of 0.80 (Figure 2). The sensitivity, specificity, positive predictive value (PPV) and negative predictive value (NPV) for each risk score were calculated (Table 6). The recurrence rate of colorectal adenomas during the 2-year follow-up period after the initial 


\begin{tabular}{|c|c|c|}
\hline Factor & OR $(95 \% \mathrm{Cl})$ & $p$ value \\
\hline${ }^{*}$ Age $\geq 65$ & $1.03(0.81-1.31)$ & 0.808 \\
\hline${ }^{*}$ Gender; Male & $1.26(0.95-1.67)$ & 0.106 \\
\hline${ }^{*} \mathrm{BMI} \geq 25 \mathrm{~kg} / \mathrm{m}^{2}$ & $1.97(1.49-2.61)$ & $<0.001$ \\
\hline *Current alcohol consumption; Yes & $0.90(0.71-1.15)$ & 0.407 \\
\hline${ }^{*}$ Current cigarette smoking; Yes & $1.39(1.08-1.79)$ & 0.011 \\
\hline *Hypertension; Yes & $1.33(1.05-1.70)$ & 0.019 \\
\hline Diabetes Mellitus; Yes & $1.83(1.39-2.41)$ & $<0.001$ \\
\hline Dyslipidemia; Yes & $1.52(1.17-1.96)$ & 0.001 \\
\hline${ }^{*} \mathrm{FBG} \geq 126 \mathrm{mg} / \mathrm{dl}$ & $2.73(2.01-3.71)$ & $<0.001$ \\
\hline $\mathrm{HbA} 1 \mathrm{C} \geq 6.5 \%$ & $2.41(1.74-3.35)$ & $<0.001$ \\
\hline $\mathrm{TC} \geq 220 \mathrm{mg} / \mathrm{dl}$ & $1.31(0.97-1.78)$ & 0.080 \\
\hline $\mathrm{HDL}-\mathrm{C}<40 \mathrm{mg} / \mathrm{dl}$ & $1.30(0.89-1.92)$ & 0.176 \\
\hline${ }^{*} \mathrm{LDL}-\mathrm{C} \geq 140 \mathrm{mg} / \mathrm{dl}$ & $1.60(1.12-2.28)$ & 0.010 \\
\hline *TG $\geq 150 \mathrm{mg} / \mathrm{dl}$ & $1.94(1.48-2.56)$ & $<0.001$ \\
\hline $\begin{array}{l}\text { *Morphology of the largest } \\
\text { adenoma; Non-polypoid lesion }\end{array}$ & $2.49(1.70-3.64)$ & $<0.001$ \\
\hline $\begin{array}{l}*>20 \% \text { Villous features of } \\
\text { the largest adenoma; Yes }\end{array}$ & $2.07(1.59-2.70)$ & $<0.001$ \\
\hline $\begin{array}{l}\text { *Degree of differentiation of } \\
\text { the largest adenoma; high grade }\end{array}$ & $3.38(2.57-4.43)$ & $<0.001$ \\
\hline $\begin{array}{l}\text { *Location of the largest adenoma; } \\
\text { Right-sided colon }\end{array}$ & $1.31(1.03-1.66)$ & 0.028 \\
\hline *Diameter of the largest adenoma $\geq 10 \mathrm{~mm}$ & $5.22(4.03-6.76)$ & $<0.001$ \\
\hline *Number of the removed adenomas $\geq 3$ & $9.09(6.89-11.99)$ & $<0.001$ \\
\hline
\end{tabular}

*Risk factors that were used in multivariate analysis.

colonoscopy, the number of cases showing adenoma recurrence and the total number of cases for each score are also shown in Table 6 . When the cutoff value for the risk score was set at 3 , the odds ratio of $\geq 3$ points (3-10 points) relative to $<3$ points ( $0-2$ points) for adenoma recurrence was determined to be 7.07 (95\% CI 5.30-9.43). In those cases where the risk score was $\geq 3$ (3-10) points, the colorectal adenoma recurrence rate during the 2-year period was $59.8 \%$, and the sensitivity, specificity, PPV and NPV of the detection of adenoma recurrence were determined to be $83.2 \%, 58.8 \%, 59.8 \%$ and $82.6 \%$, respectively (Table 7).

\section{Discussion}

As suggested by the AGA guidelines, we confirmed with a multivariate analysis in this study that advanced adenomas or the presence of $\geq 3$ adenomas were associated with an increased risk of colorectal adenoma recurrence [2] (note that villous features were nearly statistically significant). Furthermore, our multivariate analysis also revealed that age, 2 metabolic factors (elevated BMI,
Table 5 Multivariate analysis of risk factors for colorectal adenoma recurrence

\begin{tabular}{lcc}
\hline Factor & OR (95\% Cl) & $\boldsymbol{p}$ value \\
\hline *Age $\geq 65$ & $1.38(1.01-1.89)$ & 0.045 \\
Gender; Male & $1.00(0.69-1.44)$ & 0.999 \\
*BMI $\geq 25 \mathrm{~kg} / \mathrm{m}^{2}$ & $1.70(1.19-2.44)$ & 0.003 \\
Current alcohol consumption;Yes & $0.97(0.69-1.36)$ & 0.870 \\
Current cigarette smoking; Yes & $1.20(1.08-1.79)$ & 0.288 \\
Hypertension; Yes & $1.24(0.91-1.68)$ & 0.169 \\
*FBG $\geq 126$ mg/dl & $2.04(1.40-2.98)$ & $<0.001$ \\
LDL-C $\geq 140$ mg/dl & $1.37(0.86-2.15)$ & 0.181 \\
TG $\geq 150$ mg/dl & $1.29(0.90-1.83)$ & 0.159 \\
Morphology of the largest adenoma; & $1.06(0.58-1.54)$ & 0.825 \\
Non-polypoid lesion & $1.56(0.98-2.52)$ & 0.063 \\
* $>$ 20\% Villous features of the largest & & \\
adenoma; Yes & $2.40(1.51-3.83)$ & $<0.001$ \\
*Degree of differentiation of the & & \\
largest adenoma; high grade & $1.43(1.06-1.94)$ & 0.018 \\
*Location of the largest adenoma; & & \\
Right-sided colon & $2.89(2.07-4.04)$ & $<0.001$ \\
*Diameter of the largest adenoma $\geq 10$ mm & $6.12(4.52-8.34)$ & $<0.001$ \\
\hline *Number of the removed adenomas $\geq 3$ & & \\
*Risk factors that were adopted in our scoring system. &
\end{tabular}

increased FBG) and adenomas in the right-sided colon at the initial colonoscopy were associated with an increased risk of colorectal adenoma recurrence.

Age and gender have been reported as risk factors for the prevalence of colorectal tumors [1]. Zauber et al. demonstrated that the presence of colorectal adenomas was higher in men and among elderly people [3]. However, age and sex still remain controversial from the point of view of the risk of recurrence of adenomas [2]. In our study, age was also identified as a risk factor of recurrence, while sex was not statistically significant for recurrence.

Among patients in whom colorectal adenomas were removed at the time of the initial colonoscopy, the estimated recurrence rate at surveillance colonoscopy performed within 3-4 years has been reported as $15-60 \%$ $[16,17]$. In Japan, Yamaji et al. estimated a colorectal tumor recurrence rate of $7.2 \%$ per year in cases with no initial tumors, $19.3 \%$ per year in those with small adenomas, and $22.9 \%$ per year in those with advanced lesions [18]. In our study, the recurrence rate during a 2-year follow-up period after the initial screening colonoscopy was $42.4 \%$, being largely consistent with previous reports.

At the time of surveillance colonoscopy, it is often difficult to differentiate between actual recurrence and detection of an adenoma missed in the earlier examination. On the other hand, from the clinical standpoint, strict differentiation between the two is not always necessary. Irrespective of whether the lesions identified 


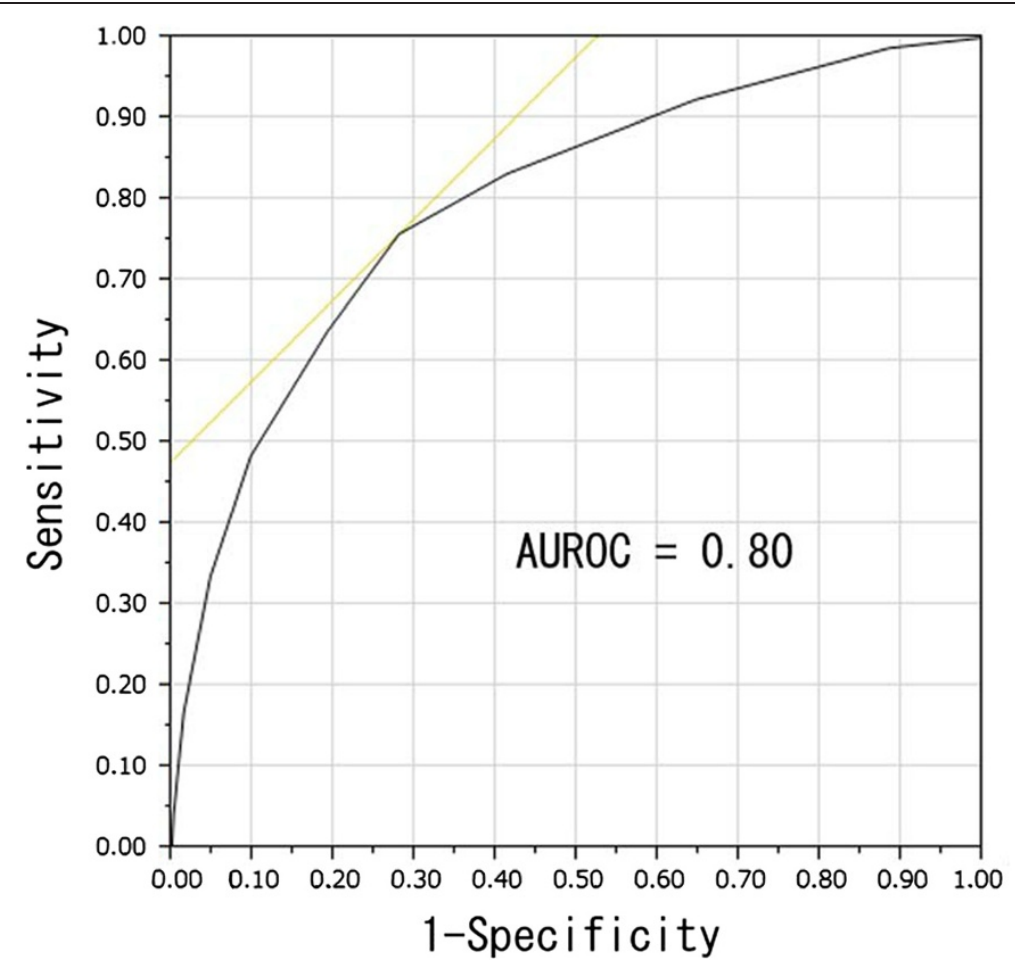

Figure 2 ROC curve for the risk score and recurrence. The AUROC for recurrence was determined to be 0.80 from ROC analysis.

on surveillance colonoscopy are recurrent or missed lesions, the lesions need to be removed. In our study, the recurrence rate at the 1-year surveillance colonoscopy was $28.2 \%$, while that at the 2 -year surveillance colonoscopy was $14.2 \%$. This is possibly because of a substantial reduction of the miss rate resulting from the 2-year surveillance colonoscopy having been conducted after 2 earlier colonoscopies (initial and at 1 year). For the same reason, the recurrence rate at the 2-year surveillance colonoscopy $(14.2 \%)$ is more likely to be closer to the actual recurrence rate per year. This rate is largely consistent with the rate reported by Yamaji et al. [18]. Furthermore, the difference in the recurrence rate between the 1-year and 2-year follow-up colonoscopies was $14.0 \%(=28.2 \%-14.2 \%)$, which may correspond to the miss rate of detection. Rex et al. reported that the miss rate for adenomas $\geq 10 \mathrm{~mm}$ in diameter was $6 \%$, for adenomas $6-9 \mathrm{~mm}$ in diameter was $13 \%$, and for adenomas $\leq 5 \mathrm{~mm}$ in diameter was 27\% [19]. Pickhardt et al. reported from their virtual colonoscopy study that conventional colonoscopy failed to detect $12 \%$ of lesions $\geq 10 \mathrm{~mm}$ in diameter [20]. Our results were consistent with these miss rates.

Table 6 ROC analysis for the risk score and recurrence rate $(\mathbf{n}=1111)$

\begin{tabular}{cccccc}
\hline Risk score & Sensitivity (\%) & Specificity (\%) & PPV (\%) & NPV (\%) & Recurrence rate $^{\mathbf{a}}$ \\
\hline 0 & 100.0 & 0.0 & 42.4 & 100.0 & $7.5(6 / 80)$ \\
1 & 98.7 & 11.6 & 45.1 & 92.5 & $16.4(30 / 183)$ \\
2 & 92.4 & 35.5 & 51.3 & 86.3 & $22.4(43 / 192)$ \\
3 & 83.2 & 58.8 & 59.8 & 82.6 & $29.2(35 / 120)$ \\
4 & 75.8 & 72.0 & 66.6 & 80.2 & $50.0(57 / 114)$ \\
5 & 63.7 & 80.9 & 71.1 & 75.2 & $54.6(72 / 132)$ \\
6 & 48.4 & 90.3 & 78.6 & 70.4 & $68.6(70 / 102)$ \\
7 & 33.6 & 95.3 & 84.0 & 66.1 & $79.0(79 / 100)$ \\
9 & 16.8 & 98.6 & 89.8 & 61.7 & $88.1(59 / 67)$ \\
10 & 4.3 & 99.8 & 95.2 & 58.6 & $93.8(15 / 16)$ \\
\hline
\end{tabular}

${ }^{a}$ Recurrence rate during the 2-year period after the initial colonoscopy (\%) (number of cases showing recurrence/total number of cases, for each risk score). 
Table 7 Cutoff value of the risk score for predicting recurrence $(n=1111)$

\begin{tabular}{cccc}
\hline $\begin{array}{c}\text { Risk } \\
\text { score }\end{array}$ & \multicolumn{2}{c}{ Recurrence } & Total \\
\cline { 2 - 3 } & Present & Absent & \\
\hline $0-2$ & 79 & 376 & 455 \\
$3-10$ & 392 & 264 & 656
\end{tabular}

The odds ratio was 7.07 (95\% Cl 5.30-9.43) (0-2 vs. 3-10).

The recurrence rate for the risk score 3-10 was 59.8\% (392/656).

The sensitivity, specificity, PPV and NPV of a risk score 3-10 for the prediction of recurrence were $83.2 \%, 58.8 \%, 59.8 \%$ and $82.6 \%$, respectively.

The main pathophysiological abnormality associated with increased levels of metabolic factors is visceral fat deposition. Visceral fat deposition is known to be associated with insulin resistance, hyperinsulinemia and high levels of IGF I, which are thought to influence carcinogenic processes by increasing the cell proliferative activities and reducing apoptosis [8,21]. Obesity-related inflammation and oxidative stress are also thought to increase the risk of development of colorectal tumors [22]. Visceral adipose tissue is considered to be an endocrine tissue, as it releases some inflammatory cytokines such as C-reactive protein, tumor necrosis factor, interleukin-6, and some adipocytokines such as leptin and adiponectin [23]. These cytokines and adipocytokines are considered to increase the risk of development, as well as the growth, of colorectal tumors. These may be the mechanisms underlying the reported increased prevalence of colorectal adenoma associated with metabolic factors. In this study, we demonstrated with the multivariate analysis that BMI was associated with the risk of recurrence of colorectal adenomas.

Diabetes mellitus is known to be associated with an increased prevalence of CRC [4], although its association with the prevalence of colorectal adenomas has not yet been sufficiently investigated. Nevertheless, among patients with obesity, a strong correlation has been reported between the presence of adenomas and diabetes mellitus [5]. Three factors, namely a present history of diabetes mellitus, FBG and HbA1c, had collinearity. In our study, FBG was used in the multivariate analysis, because its odds ratio was maximum in the univariate analysis among these 3 factors. FBG then remained as a statistically significant risk factor of colorectal adenoma recurrence in the multivariate analysis.

Some studies have reported that metabolic factors may be strongly associated with the presence of adenomas in the right-sided colon and multiple (three or more) adenomas $[8,24]$. On the other hand, screening colonoscopy has been found to confer less protection against future development of CRC in the case of right-sided than leftsided adenomas $[16,25]$. Poorer preparation and a more unfavorable anatomic configuration of the right-sided colon compromising the visibility of lesions are possible reasons for the higher miss rates of adenomas in the right-sided colon than in the left-sided colon [16]. In our study, location of the largest adenoma in the right-sided colon was also identified as a risk factor for recurrence. Therefore, endoscopists should pay particular attention to the right side of the colon, both at the time of the initial screening colonoscopy and at the time of the surveillance colonoscopy. It must be emphasized here that sigmoidoscopy is not adequate for surveillance after removal of adenomas.

Our study demonstrated that the higher the risk score, the higher the recurrence rate. ROC analysis revealed 3 as the optimal cutoff value as the risk score for predicting the risk of colorectal adenoma recurrence during the 2 -year period from the initial colonoscopy, as it was associated with a very high AUROC and sensitivity. In those cases where the risk score was $\geq 3$ points $(3-10$ points), the 2 -year colorectal adenoma recurrence rate was calculated to be $59.8 \%$ (sensitivity $83.2 \%$ ). Therefore, surveillance colonoscopy within 2 years may be a safe option for these patients.

Our study had some limitations. We were unable to obtain any waist circumference data. so it was impossible to analyze the association between the presence/absence of metabolic syndrome and colorectal adenoma recurrence.

Recently, colonoscopic quality indicators such as adenoma detection rates, withdrawal time and cecal intubation time are proposed. But these data couldn't be obtained from medical records retrospectively. Each 5 hospitals conduct 2000-6000 colonoscopies per year, and all of colonoscopists in 5 hospitals were certified from Japan gastroenterological endoscopy society. Then, recurrence rate of adenoma of 5 hospitals ranged from $40.6 \%$ to $43.7 \%$ ( $p=0.9766)$. There were no significant differences in recurrence rate between 5 hospitals. So, the bias according to the colonoscopists guess to be small.

Most of the participants of this study were followed up for only 2 years after the initial screening colonoscopy; and only a few patients were followed up for 3 years or more. Therefore, we could not collect the 3-year surveillance data.

A recent study has suggested that the use of aspirin or NSAIDs may be associated with a reduced prevalence of adenomas, and probably cancer [26]. However, among the participants who were eligible for analysis in this study, only 31 were taking aspirin/NSAIDs, and they were excluded from this study because the sample size was too small to allow reasonable analysis.

Family history of CRC has been reported as a risk factor for colorectal adenoma recurrence [2]. However, according to the medical records, the number of patients with a family history of CRC among the eligible participants was insufficient to allow reliable statistical analysis. Therefore, we did not include this factor in the analyses in our study.

Further prospective studies using larger sample sizes may be warranted to determine the risk of colorectal adenoma 
recurrence at 3 years or later after screening colonoscopy, as well as that associated with the above factors.

\section{Conclusions}

In addition to the risk factors included in the AGA guidelines, we demonstrated that age, BMI, FBG and adenomas located in the right-sided colon were associated with an increased risk of development of recurrent colorectal adenomas after removal of adenomas at the initial colonoscopy. Based on this finding, we then constructed a scoring system to predict the recurrence rate according to our risk score.

\section{Competing interests}

The authors declare that they have no competing interests.

\section{Authors' contributions}

TU, EU, SU, FJ, JH, HN, NM, have made substantial contributions to acquisition of data. YK participated in the design of the study and performed the statistical analysis. $L T, T H, H K, Y H, H E, H T, A N$ conceived of the study, and participated in its design and coordination. All authors read and approved the final manuscript.

\section{Acknowledgements}

This work was supported in part by a Grant-in-Aid for research on the Third-Term Comprehensive Control Research for Cancer from the Ministry of Health, Labour and Welfare, Japan, to A. Nakajima.

\section{Author details}

'Department of Gastroenterology, Chigasaki Municipal Hospital, Chigasaki, Japan. 'Division of Gastroenterology, Yokohama City University School of Medicine, 3-9 Fukuura, Kanazawa-ku, 236-0004 Yokohama, Kanagawa, Japan. ${ }^{3}$ Department of Endocrinology and Metabolism, Chigasaki Municipal Hospital, Chigasaki, Japan. ${ }^{4}$ Department of Gastroenterology, Yokohama Rousai Hospital, Yokohama, Japan. ${ }^{5}$ Department of Gastroenterology, Tokyo Metropolitan Hiroo Hospital, Tokyo, Japan. ${ }^{6}$ Department of Gastroenterology, Machida Municipal Hospital, Machida, Japan. ${ }^{7}$ Department of Gastroenterology, Kanto Medical Center, NTT EC, Tokyo, Japan.

Received: 14 March 2014 Accepted: 15 October 2014

Published: 23 October 2014

\section{References}

1. Siegel R, Desantis C, Jemal A: Colorectal cancer statistics, 2014. CA Cancer J Clin 2014, 64(2):104-117.

2. Lieberman DA, Rex DK, Winawer SJ, Giardiello FM, Johnson DA, Levin TR: Guidelines for colonoscopy surveillance after screening and polypectomy: a consensus update by the US Multi-Society Task Force on Colorectal Cancer. Gastroenterology 2012, 143(3):844-857.

3. Zauber AG, Winawer SJ, O'Brien MJ, Lansdorp-Vogelaar I, van Ballegooijen M, Hankey BF, Shi W, Bond JH, Schapiro M, Panish JF, Stewart ET, Waye JD: Colonoscopic polypectomy and long-term prevention of colorectal-cancer deaths. N Engl J Med 2012, 366(8):687-696.

4. Limburg PJ, Anderson KE, Johnson TW, Jacobs DR Jr, Lazovich D, Hong CP, Nicodemus KK, Folsom AR: Diabetes mellitus and subsite-specific colorectal cancer risks in the lowa Women's Health Study. Cancer Epidemiol Biomarkers Prev 2005, 14(1):133-137.

5. Elwing JE, Gao F, Davidson NO, Early DS: Type 2 diabetes mellitus: the impact on colorectal adenoma risk in women. Am J Gastroenterol 2006, 101(8):1866-1871.

6. Otani T, Iwasaki M, Ikeda S, Kozu T, Saito H, Mutoh M, Wakabayashi K, Tsugane S: Serum triglycerides and colorectal adenoma in a case-control study among cancer screening examinees (Japan). Cancer Causes Control 2006, 17(10):1245-1252.

7. Liu CS, Hsu HS, Li Cl, Jan Cl, Li TC, Lin WY, Lin T, Chen YC, Lee CC, Lin CC: Central obesity and atherogenic dyslipidemia in metabolic syndrome are associated with increased risk for colorectal adenoma in a Chinese population. BMC Gastroenterol 2010, 10:51.
8. Kim JH, Lim YJ, Kim YH, Sung IK, Shim SG, Oh SO, Park SS, Yang S, Son HJ, Rhee PL, Kim JJ, Rhee JC, Choi YH: Is metabolic syndrome a risk factor for colorectal adenoma? Cancer Epidemiol Biomarkers Prev 2007, 16(8):1543-1546.

9. Orannapalai N, Attawettayanon W, Kanngern S, Boonpipattanapong T, Sangkhathat S: Predicting the occurrence of cancer-associated colorectal polyp using a metabolic risk score. Mol Clin Oncol 2013, 2(1):124-128.

10. Giovannucci $E$, Michaud D: The role of obesity and related metabolic disturbances in cancers of the colon, prostate, and pancreas. Gastroenterology 2007, 132(6):2208-2225.

11. Paggi S, Rondonotti $E$, Amato A, Terruzzi V, Imperiali G, Mandelli G, Terreni N, Lenoci N, Spinzi G, Radaelli F: Resect and discard strategy in clinical practice: a prospective cohort study. Endoscopy 2012, 44(10):899-904.

12. Jensen MD, Ryan DH, Apovian CM, Ard JD, Comuzzie AG, Donato KA, Hu FB Hubbard VS, Jakicic JM, Kushner RF, Loria CM, Millen BE, Nonas CA, Pi-Sunyer FX, Stevens J, Stevens VJ, Wadden TA, Wolfe BM, Yanovski SZ: AHA/ACC/TOS guideline for the management of overweight and obesity in adults: a report of the American College of Cardiology/American Heart Association Task Force on practice guidelines and the obesity society. J Am Coll Cardiol 2013, 63(25 Pt B):2985-3023.

13. Committee to Evaluate Diagnostic Standards for Metabolic Syndrome: Definition and the diagnostic standard for metabolic syndrome [in Japanese]. Nippon Naika Gakkai Zasshi 2005, 94:794-809.

14. 囚: Executive summary: standards of medical care in diabetes-2014. Diabetes Care 2014, 37(Suppl 1):S5-S13. doi: 10.2337/dc14-S005.

15. Teramoto T, Sasaki J, Ishibashi S, Birou S, Daida H, Dohi S, Egusa G, Hiro T, Hirobe K, lida M, Kihara S, Kinoshita M, Maruyama C, Ohta T, Okamura T, Yamashita S, Yokode M, Yokote K: Diabetes mellitus: executive summary of the Japan Atherosclerosis Society (JAS) guidelines for the diagnosis and prevention of atherosclerotic cardiovascular diseases in Japan-2012 version. J Atheroscler Thromb 2014, 21(2):93-98.

16. Bressler B, Paszat LF, Chen Z, Rothwell DM, Vinden C, Rabeneck L: Rates of new or missed colorectal cancers after colonoscopy and their risk factors: a population-based analysis. Gastroenterology 2007, 132(1):96-102.

17. Lieberman DA, Weiss DG, Harford WW, Ahnen DJ, Provenzale D, Sontag SJ, Schnell TG, Chejfec G, Campbell DR, Kidao J, Bond JH, Nelson DB, Triadafilopoulos G, Ramirez FC, Collins JF, Johnston TK, McQuaid KR, Garewal H, Sampliner RE, Esquivel R, Robertson D: Five-year colon surveillance after screening colonoscopy. Gastroenterology 2007, 133(4):1077-1085.

18. Yamaji Y, Mitsushima T, Ikuma H, Watabe H, Okamoto M, Kawabe T, Wada R, Doi $\mathrm{H}$, Omata $\mathrm{M}$ : Incidence and recurrence rates of colorectal adenomas estimated by annually repeated colonoscopies on asymptomatic Japanese. Gut 2004, 53(4):568-572.

19. Rex DK, Cutler CS, Lemmel GT, Rahmani EY, Clark DW, Helper DJ, Lehman GA, Mark DG: Colonoscopic miss rates of adenomas determined by back-to-back colonoscopies. Gastroenterology 1997, 112(1):24-28.

20. Pickhardt PJ, Choi JR, Hwang I, Butler JA, Puckett ML, Hildebrandt HA, Wong RK, Nugent PA, Mysliwiec PA, Schindler WR: Computed tomographic virtual colonoscopy to screen for colorectal neoplasia in asymptomatic adults. N Engl J Med 2003, 349(23):2191-2200.

21. Giorgino F, Laviola L, Eriksson JW: Regional differences of insulin action in adipose tissue: insights from in vivo and in vitro studies. Acta Physiol Scand 2005, 183(1):13-30.

22. Cowey S, Hardy RW: The metabolic syndrome: a high-risk state for cancer? Am J Pathol 2006, 169(5):1505-1522.

23. Trayhurn $\mathrm{P}$, Beattie $\mathrm{JH}$ : Physiological role of adipose tissue: white adipose tissue as an endocrine and secretory organ. Proc Nutr Soc 2001, 60(3):329-339.

24. Chiu HM, Lin JT, Shun CT, Liang JT, Lee YC, Huang SP, Wu MS: Association of metabolic syndrome with proximal and synchronous colorectal neoplasm. Clin Gastroenterol Hepatol 2007, 5(2):221-229. quiz 141.

25. Singh H, Nugent Z, Demers AA, Kliewer EV, Mahmud SM, Bernstein CN: The reduction in colorectal cancer mortality after colonoscopy varies by site of the cancer. Gastroenterology 2010, 139(4):1128-1137.

26. Din FV, Theodoratou E, Farrington SM, Tenesa A, Barnetson RA, Cetnarskyj R, Stark L, Porteous ME, Campbell H, Dunlop MG: Effect of aspirin and NSAIDs on risk and survival from colorectal cancer. Gut 2010, 59(12):1670-1679.

\section{doi:10.1186/1471-230X-14-187}

Cite this article as: Taniguchi et al:: Metabolic factors accelerate colorectal adenoma recurrence. BMC Gastroenterology 2014 14:187. 